\title{
Ortaokul Öğrencilerinde Dijital Oyun Bağımlılığının Fiziksel Aktivite ve Uyku Alışkanlıklarına Etkisi
}

\section{The Effect of Digital Game Addiction on Physical Activity and Sleep Habits in Secondary School Students}

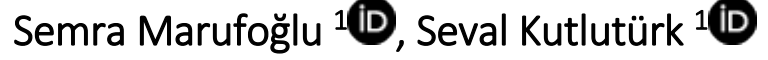 \\ 1. ̇̇stanbul Medipol Üniversitesi, Sağlık Bilimleri Enstitüsü, Fizyoterapi ve Rehabilitasyon Tezli Yüksek Lisans Programı, İstanbul \\ 2. İstanbul Medipol Üniversitesi, Sağlık Bilimleri Fakültesi, Fizik Tedavi ve Rehabilitasyon Anabilim Dalı, İstanbul
}

\begin{abstract}
Objective: The aim of this study is to investigate the effect of digital game addiction on physical activities and sleep habits of secondary school students.

Method: The study was conducted on 100 middle school students (F: 56, M: 44) who were 5th, 6th, 7th and 8th grades. Students' digital game addiction was evaluated by the Digital Game Addiction Scale for Children (DGAS-C), physical activity levels was evaluated by the Primary School Students' Physical Activity Questionnaire (PAQ), sleep habits was evaluated by Children's Sleep Habits Questionnaire (CSHQ).

Results: There was no statistically significant relationship between DGAS-C and its subgroups and FAQ). There was no statistically significant difference between students' digital play and sleep habits. Students who played digital games for more than 3 hours and more than 3 hours were found to have higher levels of digital game addiction compared to other students. Fifth grade students were found to have higher physical activity levels than 7 th and 8th grade students.

Conclusion: In this study, no relationship was found between digital game addiction and physical activity and sleep habits of secondary school students. These results may be due to the fact that students' access to digital tools is under parental control and limited access of children to digital game tools for economic reasons.
\end{abstract}

Keywords: Adolescent, digital game addiction, physical activity, sleep habits

Öz

Amaç: Çalısmanın amacı, ortaokul öğrencilerinde dijital oyun bağımlıı̆ının fiziksel aktivite ve uyku alışkanlıklarına olan etkisini araştırmaktır.

Yöntem: Çalışma, yaşları 9-14 arasında olan 100 ortaokul öğrencisi (K:56, E:44) üzerinde yapıımıştır. Dijital oyun bağımlılığı Çocuklar Için Dijital Oyun Bağımlılığı Ölçeği (ÇiDOBÖ) ile, fiziksel aktivite düzeyleri Illköğretim Öğrencileri Fiziksel Aktivite Soru Formu (FAS) ile, uyku alışkanlıkları ise Çocuk Uyku Alışkanlıkları Anketi (ÇUAA) ile değerlendirilmiş̧tir.

Bulgular: ÇiDOBÖ ve alt parametreleri ile FAS arasında istatistiksel olarak anlamlı bir ilişki saptanmamıştır. Öğrencilerin dijital oyun oynama durumu ile uyku alışkanlıkları arasında da istatistiksel olarak anlamlı bir farklılık olmadığı sonucuna ulaşılmıştır. Dijital oyunları 3 saat ve 3 saatten fazla oynayan öğrencilerin dijital oyun bağımlı̆ğı düzeylerinin diğer öğrencilere göre yüksek olduğu görülmüştür. Beşinci sınıf öğrencilerinin 7 . ve 8. sınıf öğrencilerine göre fiziksel aktivite düzeylerinin daha yüksek olduğu görülmüştür.

Sonuç: Çalışmada ortaokul öğrencilerinin dijital oyun bağımlıı̆ı ile fiziksel aktivite düzeyleri ve uyku alışkanlıkları arasında anlamlı bir ilişki olmadığı tespit edilmişsir. Öğrencilerin dijital araçlara erişiminin ebeveyn kontrolü altında olması ve ekonomik nedenlerle çocukların dijital oyun araçlarına sınırlı erişimleri nedeni ile bu sonuçların ortaya çıkı̆ğını düşünmekteyiz.

Anahtar kelimeler: Dijital oyun bağımlılığı, fiziksel aktivite, uyku alışkanlıkları 


\section{Giriş}

Bilgi ve iletişim teknolojilerinin hızlı gelişimi ile birlikte internet ve bilgisayar kullanımı birçok alanda insan yaşamını kolaylaştııırken oyun ve eğlence aracı olarak kullanımı da yaygınlaşmaktadır (1). Özellikle çocuk ve gençler tarafından yoğun ilgi gösterilen dijital oyunların neredeyse her yaştan kullanıcısı bulunmakta ve oyun oynayarak geçirilen süredeki artış ile birlikte dijital oyun bağımlılı̆ından söz edilmeye başlanmıştır (24). Dijital oyun bağımlılığı çocukların ve gençlerin oyun oynama isteğini ve süresini kontrol edememeleri, bu hayali durumu gerçek yaşantılarıla ilişkilendirmeleri, sorumluluklarını inmal etmeleri ve dijital oyunu yapılması gereken öncelikli işleri gibi görmeleri olarak tanımlanmaktadır (5).

Genç bireylerin devamlı bilgisayar başında olması; iletişimsizlik, yalnızlık, depresyon, davranış problemleri ve karar verme yeteneğinin azalması gibi birçok olumsuz psikososyal sonuçların yanı sıra bireyleri uzun süreli hareketsizliğe sürüklemektedir (6-8). Telefon bilgisayar gibi cihazların aşııı kullanımı, obezite, baş ağrısı, anksiyete, stres, kas-iskelet sistemi ağrısı ve azalmış fiziksel aktivite seviyesi gibi çeşitli sağlık sorunları ile ilişkilendirilmiş̧ir $(4,9)$. Yapılan çalışmaların sonuçları dijital çağın ilerleyici olarak çocukların egzersiz alışkanlığında gözle görülür bir düşüşe neden olduğunu göstermektedir (10,11). Adölesanların uyku intiyaçlarının uygun düzeyde ve kalitede karşılanamamasında biyolojik, psikososyal ve çevresel sebeplerin olduğu ve çevresel sebeplerin arasında bilgisayar, telefon, tablet, video oyunları ve kontrolsüzce televizyon izleme alışkanlıklarının önemli yeri olduğu bildirilmiştir (12).

Literatürü incelendiğinde dijital oyun bağımlıı̆̆ ve ilişkili olabileceği düşünülen fiziksel aktivite ve uyku alışkanlıklarını bir arada ele alan ve bu parametrelerin ilişkisini gösteren detaylı çalışmaların yapılması gerektiği düşünülmüştür. Bu çalışmanın amacı ortaokul öğrencilerinde teknoloji ile birlikte ortaya çıkan ve hızla yaygınlaşmakta olan dijital oyun bağımlıı̆ı düzeyi, fiziksel aktivite seviyesi ve uyku alışkanlıklarının belirlenmesi ve bu parametreler arasındaki ilişkiyi araştırmaktır.

\section{Yöntem}

\section{Örneklem}

Çalışmaya, Aralık 2019 - Ocak 2020 tarihleri arasında Van ili Erciş ilçesinde bulunan Tenzile Ana Ortaokulu ile Cumhuriyet Ortaokulu'nda eğitim öğretim gören ortaokul çocukları ve aynı çocukların ebeveynleri katıldı. Çalışma için gerekli izinler Millî Eğitim Bakanlığı Erciş İlçe Milli Eğitim Müdürlüğü'nden 19/12/2019 tarihli E.25354465 sayı numarası ile alındı. Araştırmacı gönüllülük esasına dayalı olarak katılan tüm çocuk ve ebeveynlerle yüz yüze görüşerek çalışma ile ilgili sözlü ve yazılı bilgilendirme yolu ile onamlarını aldıktan sonra ölçekler uygulamış ve verileri toplamıştır. Çalışmaya Tenzile Ana Ortaokulu ile Cumhuriyet Ortaokulu'nda eğitim gören, son yedi gün içinde fiziksel olarak aktif olmalarına engel bir durum bulunmayan ve katımaya gönüllü olan bireyler dahil edildi. Fiziksel, nörolojik, bilişsel ve kronik herhangi bir hastalığı olan bireyler çalışmaya dahil edilmedi.

Çalışmaya katılan kişi sayısı G* Power programı 3.1.9.5 versiyonu kullanılarak belirlendi. Tip-1 hata oranı 0,05 ve güç oranı \%80 olarak kabul edildi. Hazar ve ark.'nın yaptığı referans çalışmanın verileri kullanılarak etki büyüklüğü 0,3 olarak alındı (13). Güç analizi sonuçlarına göre çalışmaya alınması gereken kişi sayısı 84 olarak belirlendi. Uygulama esnasındaki veri kayıpları da dikkate alınarak 100 çocuk ve bu çocukların ebeveynleri üzerinde çalışma yürütüldü.

\section{İşlem}

Bu araştırma, İstanbul Medipol Üniversitesi Girişimsel Olmayan Klinik Çalışmalar Etik Kurulu Başkanlı̆ı̆'nın 09.01.2020 tarihli, 10840098-604.01.01-E.859 dosya numarası ile onaylandıktan sonra gerçekleştirildi. Tüm katılımcılar çalışmaya dahil olmadan önce aydınlatılmış onam verdi. Katılımcıların adı, soyadı, yaşı, cinsiyeti, kaçıncı sınıfta olduğu, ebeveynlerinin eğitim düzeyi, aylık gelirleri ve katılımcıların dijital oyun 
oynayıp oynamadığı, oynuyorsa günde kaç saat oynadığı ile ilgili bilgiler, araştırmacı tarafından hazırlanan kişisel değerlendirme formuna kaydedildi. Daha sonra katılımcılara çeşitli ölçekler verildi.

\section{Veri Toplama Araçları}

Araştırmada katıımcıların dijital oyun bağımlı̆̆ğ, fiziksel aktivite ve uyku alışkanlıklarını değerlendirmek için aşağıda belirtilen ölçekler kullanılmıştır.

\section{Dijital Oyun Bağımlıı̆ının Değerlendirilmesi}

Katılımcıların dijital oyun bağımlılığının değerlendirilmesi; Çocuklar İçin Dijital Oyun Bağımlılık Öıçeği (ÇiDOBÖ) kullanılarak yapıldı. Bu ölçek Hazar ve arkadaşları tarafından sorunlu dijital oyun oynama davranışlarını belirlemek amacıyla geliştirilmiştir. Ölçeğin dijital oyun oynamaya yönelik aşıı odaklanma ve çatışma, oyun süresinde tolerans gelişimi, oyuna yüklenen değer, bireysel ve sosyal görevlerin/ödevlerin ertelenmesi ve yoksunluğun psikolojik-fizyolojik yansıması ve oyuna dalma olmak üzere toplam dört alt boyutu bulunmaktadır. Ölçeğin bütünü için Cronbach Alfa iç tutarlılık kat sayısı .90, birinci faktör için .78, ikinci faktör için .81, üçüncü faktör için .76 ve dördüncü faktör için .67 olarak elde edilmiştir. Bu ölçekten alınan puanlara göre; 1-24 puan: Normal, 25-48 puan: Az Riskli, 49-72 puan: Riskli, 73-96 puan: Bağımlı ve 97-120 puan: Yüksek düzeyde bağımlı grup olarak ifade edilmektedir (14).

\section{Fiziksel Aktivitenin Değerlendirilmesi}

İlköğretim Öğrencileri Fiziksel Aktivite Soru Formu (FAS), 1997 yılında Kowalski ve ark., tarafından oluşturulan bir ankettir. FAS; Ortaöğretime devam eden öğrencilerin okul dönemi boyunca son 7 gündeki fiziksel aktivitelerini değerlendirmek için tasarlanmıştır (15). Ankete verilen cevapların 1 ile 5 arasında puanlandığı 9 soru ve geçen hafta boyunca fiziksel aktivite yapmaya engel bir durum olup olmadığını sorgulayan 10. sorudan oluşmaktadır. '1' puan düşük şiddette fiziksel aktiviteye, '5' puan ise yüksek şiddette fiziksel aktiviteye karşıllk gelir, ancak son soru puanlamaya katılmamaktadır. Toplam puan tüm soruların ortalama puanı hesaplanarak elde edilir. Ölçekten elde edilebilecek minimum puan 9, maksimum puan $45^{\prime}$ tir. Bu anketin Türkçe geçerlik ve güvenirlik çalışması Sert ve arkadaşları tarafından yapılmıştır. Ölçeğin Cronbach Alfa katsayısı .74 olarak saptanmıştı (16).

\section{Uyku Alışkanlıklarının Değerlendirilmesi}

Öğrencilerin uyku alışkanlıkları Çocuk Uyku Alışkanlıkları Anketi (ÇUAA) ile değerlendirildi. Ölçek Owens ve ark. (17) tarafından çocuklarda uyku alışkanlıkları ve uyku ile ilgili sorunları belirlemek amacıyla geliştirilmiş̧ir. Fiş ve arkadaşları (18) tarafından Türkçe güvenilirlik ve geçerlilik çalışması yapılan bu ölçeğin bütünü için Cronbach alfa değeri .78 olarak bulunmuştur. Ölçeğin kısaltılış formu toplam 33 maddeden oluşmaktadır. Ölçek, çocuğun anne veya babası tarafından doldurulmakta, anne ve/veya babadan çocuğun uyku alıskanlıklarını geçtiğimiz hafta göz önüne alınarak değerlendirmeleri istenmektedir. Öıçeğin yatma zamanı direnci, uykuya dalmanın gecikmesi, uyku süresi, uyku kaygısı, gece uyanmaları, parasomniler, uykuda solunumun bozulması, gün içinde uykululuk şeklinde sıralanabilen sekiz alt ölçeği bulunmaktadır. Ölçekten elde edilen 41 puan kesim noktası olarak kabul edilmekte ve bunun üzerindeki değerler klinik açıdan anlamlı kabul edilmektedir (17).

\section{Veri Analizi}

Çalışmadan elde edilen veriler; "Statistical Processing For The Social Sciences Software (SPSS 21.0, Inc, Chicago, Illinois)" programı kullanılarak analiz edilmiştir. Katılımcıların demografik bilgilerine ilişkin frekans ve yüzde dağıımları çıkarıldı. Katılımcıların sosyodemografik, özellikleri ile ölçekler arasındaki karşılaştırmalarda, iki grup ortalamalarını karşılaştırmada normal dağılım gösteren verilerde t testi, normal dağılım göstermeyen verilerde ise Mann Whitney U testi kullanıldı. Üç ve daha fazla bağımsız ortalama arasındaki farkın hesaplanmasında; veriler normal dağılım gösterdiğinde ANOVA, normal dağılım göstermediğinde Kruskal-Wallis testi kullanıldı. Ortalamalar arasında farklar bulunduğu takdirde ortalamalar arasındaki farkları eşzamanlı olarak karşılaştırmayı sağlayan post hoc Tukey HSD testi 
uygulandı. Parametreler arasındaki ilişkileri değerlendirmek için ise Pearson ve Spearman Korelasyon analizi kullanıldı. İstatistiksel anlamlılık düzeyi $p<0,05$ olarak kabul edildi.

\section{Bulgular}

Araştırmaya katılan yaş aralığı 9-14 olan 100 öğrencinin ortalama yaşları 11,74 1 1,30'dur. Katılımcıların büyük çoğunluğunun, kız $(n=56)$ ve 7 . sınıf öğrencisi olduğu $(n=30)$, annelerinin ortaokul $(n=27)$ ve babalarının ise lise $(n=34)$ mezunudur. Ayrıca katılımcıların \%67'si dijital oyun oynamakta, \%6'sı da günde üç saatten fazla dijital oyun oynamaktadır. Öğrencilerin cinsiyetlerine göre dijital oyun oynama durumuna bakıldığında erkek öğrencilerin \%73'ü, kız öğrencilerin ise \%63'ü olmak üzere her iki cinsiyetin çoğunluğu dijital oyun oynamaktadır.

\section{Tablo 1. Öğrencilerin Dijital Oyun Bağımllı̆ğı Ölçeğine göre bağımlılık düzeyleri}

\begin{tabular}{|l|c|}
\hline Bağımlılık Düzeyleri & N (\%) \\
\hline Normal Grup (1-24 puan) & $9(9)$ \\
\hline Az Riskli Grup (25-48 puan) & $60(60)$ \\
\hline Riskli Grup (49-72 puan) & $22(22)$ \\
\hline Bağımlı Grup (73-96 puan) & $6(6)$ \\
\hline Yüksek Düzeyde Bağımlı Grup (97-120 puan) & $3(3)$ \\
\hline Toplam & $100(100)$ \\
\hline
\end{tabular}

Tablo 2. Öğrencilerin cinsiyet, sınıf düzeyi, anne-baba eğitim düzeyi, ekonomik gelir ve okul başarııının göre dijital oyun bağımlıık düzeyleri

\begin{tabular}{|c|c|c|c|c|c|c|c|c|}
\hline Değişken & Grup & $\begin{array}{l}\text { Normal } \\
\text { Grup } \\
\text { N(\%) }\end{array}$ & $\begin{array}{l}\text { Az Riskli } \\
\text { Grup } \\
\text { N(\%) }\end{array}$ & $\begin{array}{l}\text { Riskli } \\
\text { Grup } \\
\mathrm{N}(\%)\end{array}$ & $\begin{array}{l}\text { Bağımlı } \\
\text { N(\%) }\end{array}$ & $\begin{array}{c}\text { Yüksek } \\
\text { Düzeyde } \\
\text { Bağımlı } \\
\text { Grup N(\%) }\end{array}$ & Toplam & $\mathrm{p}^{*}$ \\
\hline Cinsiyet & $\begin{array}{l}\text { KIZ } \\
\text { Erkek }\end{array}$ & $\begin{array}{c}6(10,7) \\
3(6,8)\end{array}$ & $\begin{array}{l}35(62,5) \\
25(56,8)\end{array}$ & $\begin{array}{c}11(19,6) \\
11(25)\end{array}$ & $\begin{array}{c}1(1,8) \\
5(11,4)\end{array}$ & $\begin{array}{c}3(5,4) \\
0\end{array}$ & $\begin{array}{l}56 \\
44\end{array}$ & 0,43 \\
\hline Sinif & $\begin{array}{l}\text { 8. Sinif } \\
\text { 7. Sinif } \\
\text { 6. Sinif } \\
\text { 5. Sinif }\end{array}$ & $\begin{array}{l}3(13) \\
2(6,7) \\
2(9,5) \\
2(7,7)\end{array}$ & $\begin{array}{c}13(56,5) \\
15(50) \\
12(7,1) \\
20(76,9)\end{array}$ & $\begin{array}{l}4(17,4) \\
9(30,0) \\
5(23,8) \\
4(15,4)\end{array}$ & $\begin{array}{c}0 \\
4(13,3) \\
2(9,5) \\
0\end{array}$ & $\begin{array}{c}3(13) \\
0 \\
0 \\
0\end{array}$ & $\begin{array}{l}23 \\
30 \\
21 \\
26\end{array}$ & 0,45 \\
\hline Anne Eğitimi & $\begin{array}{l}\text { Üniversite } \\
\text { Lise } \\
\text { Ortaokul } \\
\text { Illkokul } \\
\text { Eğitim yok }\end{array}$ & $\begin{array}{c}0 \\
1(11,1) \\
1(11,1) \\
2(22,2) \\
5(55,6)\end{array}$ & $\begin{array}{c}8(66,7) \\
9(60) \\
17(63) \\
12(60) \\
13(52)\end{array}$ & $\begin{array}{c}3(25) \\
1(6,7) \\
7(25,9) \\
5(25) \\
6(24)\end{array}$ & $\begin{array}{c}0 \\
3(20) \\
1(3,7) \\
1(5) \\
1(4)\end{array}$ & $\begin{array}{c}1(8,3) \\
1(6,7) \\
1(3,7) \\
0 \\
0\end{array}$ & $\begin{array}{l}12 \\
15 \\
27 \\
20 \\
25\end{array}$ & 0,42 \\
\hline Baba Eğitimi & $\begin{array}{l}\text { Üniversite } \\
\text { Lise } \\
\text { Ortaokul } \\
\text { İlkokul } \\
\text { Eğitim yok }\end{array}$ & $\begin{array}{c}3(13,6) \\
0 \\
2(8,3) \\
4(21,1) \\
0\end{array}$ & $\begin{array}{c}13(59) \\
20(58,8) \\
13(54,1) \\
13(68,42) \\
1(100)\end{array}$ & $\begin{array}{c}4(18,2) \\
8(23,5) \\
8(33,3) \\
2(10,05) \\
0\end{array}$ & $\begin{array}{c}1(4,5) \\
4(13,3) \\
1(4,16) \\
0 \\
0\end{array}$ & $\begin{array}{c}1(4,5) \\
2(5,8) \\
0 \\
0 \\
0\end{array}$ & $\begin{array}{c}22 \\
34 \\
24 \\
19 \\
1\end{array}$ & $0,03^{*}$ \\
\hline $\begin{array}{l}\text { Ailenin } \\
\text { Ekonomik } \\
\text { Durumu } \\
\text { (TL) }\end{array}$ & $\begin{array}{l}5001 \mathrm{TL} \uparrow \\
4001-5000 \\
2001-4000 \\
2000 \downarrow\end{array}$ & $\begin{array}{c}1(6,7) \\
1(4,5) \\
4(12,9) \\
3(11,5)\end{array}$ & $\begin{array}{c}9(60) \\
15(68,2) \\
16(51,6) \\
16(61,5)\end{array}$ & $\begin{array}{c}3(20) \\
5(22,7) \\
6(19,4) \\
6(23,1)\end{array}$ & $\begin{array}{l}1(6,7) \\
1(4,5) \\
3(9,7) \\
1(3,8)\end{array}$ & $\begin{array}{c}1(6,7) \\
0 \\
2(6,5) \\
0\end{array}$ & $\begin{array}{l}15 \\
22 \\
31 \\
26\end{array}$ & 0,87 \\
\hline $\begin{array}{l}\text { Öğrencinin } \\
\text { Okul Başarısı }\end{array}$ & $\begin{array}{l}\text { Düşük } \\
\text { Orta } \\
\text { lyi } \\
\text { Çok İyi }\end{array}$ & $\begin{array}{c}0 \\
2(10) \\
0 \\
7(16,7)\end{array}$ & $\begin{array}{c}3(100) \\
9(45) \\
22(62,9) \\
26(61,9)\end{array}$ & $\begin{array}{c}0 \\
7(35) \\
7(20) \\
8(19)\end{array}$ & $\begin{array}{c}0 \\
1(5) \\
5(14,3) \\
0\end{array}$ & $\begin{array}{c}0 \\
1(5) \\
1(2,9) \\
1(2,4)\end{array}$ & $\begin{array}{l}3,0 \\
20 \\
35 \\
42\end{array}$ & 0,14 \\
\hline $\begin{array}{l}\text { Dijital Oyuna } \\
\text { Harcanan } \\
\text { Vakit }\end{array}$ & $\begin{array}{l}\text { Yarım saat } \\
1 \text { saat } \\
2 \text { saat } \\
3 \text { saat } \\
3 \text { saat } \uparrow\end{array}$ & $\begin{array}{c}0 \\
1(5,3) \\
0 \\
0 \\
1(16,7)\end{array}$ & $\begin{array}{c}23(79,3) \\
12(63,1) \\
4(33,3) \\
1(14,2) \\
2(33,3)\end{array}$ & $\begin{array}{c}6(20,7) \\
6(31,6) \\
6(50) \\
3(42,9) \\
1(16,7)\end{array}$ & $\begin{array}{c}0 \\
0 \\
1(8,3) \\
3(42,9) \\
2(33,3)\end{array}$ & $\begin{array}{c}0 \\
0 \\
1(8,3) \\
0 \\
0\end{array}$ & $\begin{array}{c}29 \\
19 \\
12 \\
7 \\
6\end{array}$ & $0,001^{*}$ \\
\hline
\end{tabular}

$\phi ; p<0,005$, Mann Whitney U Testi, $\Upsilon ; p<0,005$, Kruskall-Wallis Testi 


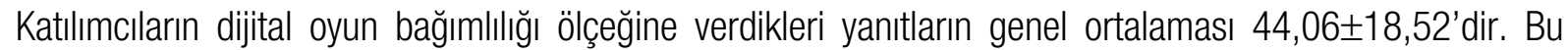
durumda katılımcılar "Az Riskli Grup" olarak değerlendirilmektedir. Frekans analizine bakıldığında 60 kişinin az riskli (25-48 puan), 6 kişinin bağımlı (73-96 puan), 9 kişinin normal (1-24 puan), 22 kişinin riskli (49-72 puan), 3 kişinin ise yüksek düzeyde bağımlı (97-120 puan) grupta olduğu tespit edildi (Tablo 1).

Katılımcıların demografik değişkenlerine bağlı olarak dijital oyun bağımlılı̆ına ilişkin farkılıkları değerlendirildiğinde; baba eğitim düzeyleri ve dijital oyuna harcanan zaman değişkenleri açısından dijital bağımlılık ölçeği puanları arasında istatistiksel olarak anlamlı fark olduğu sonucuna ulaşıldı $(p<0,05)$. Ortalamalara bakıldığında baba eğitim düzeyi "lise" olan öğrencilerin dijital bağımlılı̆ının diğer eğitim düzeylerine oranla daha yüksek olduğu ortaya konmuştur. En az bir grup iki veri girişinden daha az veri girişine sahip olduğu için bu farklılığın kaynağını belirlemek amacıyla post hoc teknikleri uygulanamamıştır. Dijital oyuna harcanan süreye bakıldığında; dijital oyunları 3 saat ve 3 saatten fazla oynayan çocukların dijital oyun bağımlılığı düzeylerinin daha yüksek olduğu görüldü $(p<0,05)$ (Tablo 2).

Tablo 3. Öğrencilerin cinsiyet, sınıf düzeyi, anne-baba eğitim düzeyi, ekonomik gelir ve okul başarısının göre fiziksel aktivite düzeyleri

\begin{tabular}{|c|c|c|c|c|}
\hline Değişken & Grup & $N$ & $\begin{array}{l}\text { Fiziksel Aktivite Anketi } \\
\text { Ortalama } \pm S S\end{array}$ & $p$ \\
\hline \multirow[t]{2}{*}{ Cinsiyet } & KIZ & 56 & $22,28 \pm 7,41$ & \multirow[t]{2}{*}{0,14} \\
\hline & Erkek & 44 & $24,36 \pm 6,39$ & \\
\hline \multirow[t]{4}{*}{ Sınıf Düzeyi } & 5.Sinif & 23 & $28,17 \pm 6,94$ & \multirow[t]{4}{*}{$0,001^{*}$} \\
\hline & 6.Sinif & 30 & $22,16 \pm 6,41$ & \\
\hline & 7.Sinıf & 21 & $20,92 \pm 5,74$ & \\
\hline & 8.Sinıf & 26 & $21,48 \pm 6,80$ & \\
\hline \multirow[t]{5}{*}{ Anne Eğitim Düzeyi } & Üniversite & 12 & $23,65 \pm 8,00$ & \multirow[t]{5}{*}{0,54} \\
\hline & Lise & 15 & $24,81 \pm 6,32$ & \\
\hline & Ortaokul & 27 & $24,28 \pm 7,91$ & \\
\hline & illkokul & 21 & $21,26 \pm 5,06$ & \\
\hline & Okur Yazar değil & 25 & $22,65 \pm 7,37$ & \\
\hline \multirow[t]{5}{*}{ Baba Eğitim Düzeyi } & Üniversite & 22 & $26,98 \pm 7,02$ & \multirow[t]{5}{*}{0,45} \\
\hline & Lise & 34 & $21,29 \pm 6,09$ & \\
\hline & Ortaokul & 24 & $22,95 \pm 6,73$ & \\
\hline & illkokul & 19 & $22,30 \pm 7,11$ & \\
\hline & Okur Yazar değil & 1 & 27,33 & \\
\hline \multirow{4}{*}{$\begin{array}{l}\text { Ailenin } \\
\text { Ekonomik Durumu }\end{array}$} & 5001 TL üstü & 15 & $26,13 \pm 7,04$ & \multirow[t]{4}{*}{$0,007^{\star}$} \\
\hline & 4001-5000 TL & 22 & $26,08 \pm 9,25$ & \\
\hline & $2001-4000 \mathrm{TL}$ & 31 & $21,09 \pm 5,34$ & \\
\hline & 2000 TL'den az & 26 & $20,37 \pm 5,55$ & \\
\hline \multirow[t]{4}{*}{ Okul Başarısı } & Çok iyi & 42 & $24,29 \pm 7,78$ & \multirow[t]{3}{*}{0,119} \\
\hline & İyi & 35 & $23,63 \pm 5,79$ & \\
\hline & Orta & 20 & $19,86 \pm 6,45$ & \\
\hline & Düşük & 3 & $24,92 \pm 9,68$ & \\
\hline \multirow{2}{*}{$\begin{array}{l}\text { Dijital Oyun Oynama } \\
\text { Durumu }\end{array}$} & Evet & 67 & $23,60 \pm 6,97$ & \multirow[t]{2}{*}{0,41} \\
\hline & Hayır & 33 & $22,38 \pm 7,17$ & \\
\hline \multirow{5}{*}{$\begin{array}{l}\text { Dijital Oyuna } \\
\text { Harcanan Vakit }\end{array}$} & 3 saatten fazla & 6 & $23,06 \pm 9,27$ & \\
\hline & 3 saat & 7 & $24,27 \pm 5,86$ & \multirow[t]{4}{*}{0,95} \\
\hline & 2 saat & 12 & $24,31 \pm 6,37$ & \\
\hline & 1 saat & 19 & $22,86 \pm 7,05$ & \\
\hline & Yarım saat & 29 & $23,19 \pm 7,91$ & \\
\hline
\end{tabular}

SS; Standart Sapma, *; $p<0,005$, ф;Mann Whitney U Testi, $\Upsilon$;Kruskall-Wallis Testi 
Öğrencilerin demografik özelliklerine bağlı olarak fiziksel aktivite düzeyleri değerlendirildiğinde; ailelerin ekonomik durumu ve öğrencilerin sınıf düzeylerine göre fiziksel aktivite düzeylerinin istatistiksel olarak anlamlı oranda farkıllaştığı görüldü. Ailenin gelir düzeyi düştükçe öğrencilerin fiziksel aktivite düzeylerinin de düştüğü tespit edildi, ayrıca öğrencilerin sınıf düzeyleri ile fiziksel aktivite ölçeği puanları arasında yapılan varyans analizi sonucunda aralarında anlamlı bir farklılık olduğu sonucuna ulaşıldı $(p<0,005)$. Tukey Çoklu Karşılaştırma Testi sonucuna göre farklıı̆ın 5. Sınıf $(\bar{x}=6,00)$ ile 7. Sinıf $(\bar{x}=7,24)$ ve 5. Sinıf $(\bar{x}=6,00)$ ile 8. Sınıf $(\overline{x=6,69)}$ arasından kaynaklandığı bulunmuştur. Bu sonuçlara göre öğrencilerin fiziksel aktivite düzeylerinin sınıf düzeyleri yükseldikçe azaldığı tespit edilmiştir $(p<0,005)$ (Tablo 3).Öğrencilerin dijital oyun oynama durumu ile fiziksel aktiviteleri arasında istatistiksel olarak anlamlı fark olmadığı görüldü $(p>0,05)$ (Tablo 4.). Öğrencilerin dijital oyun oynama durumu ile uyku alışkanlıkları arasında da istatiksel olarak anlamlı farkılık olmadığı tespit edildi ( $p>0,05)$ (Tablo 5.).

Tablo 4. Öğrencilerin dijital oyun oynama durumuna göre fiziksel aktivitesi

\begin{tabular}{|l|c|c|}
\hline Dijital Oyun Oynama Durumu $(\mathrm{N})$ & $\begin{array}{c}\text { Fiziksel Aktivite Anketi } \\
\text { Ortalama } \pm S s\end{array}$ & 0,41 \\
\hline Evet (67) & $23,60 \pm 6,97$ & \\
\hline Hayır (33) & $22,38 \pm 7,17$ & \\
\hline Toplam (100) & $23,19 \pm 7,02$ & \\
\hline
\end{tabular}

SS; Standart Sapma, $\phi$; Independent Samples T-Testi

Tablo 5. Öğrencilerin dijital oyun oynama durumuna göre uyku alışkanlıkları

\begin{tabular}{|l|c|c|}
\hline Dijital Oyun Oynama Durumu (N) & Uyku Alıskanlıkları Anketi Ortalama $\pm S s$ & P \\
\hline Evet (67) & $53,85 \pm 6,84$ \\
\hline Hayır (33) & $54 \pm 7,51$ & \\
\hline Toplam (100) & $53,90 \pm 6,42$ \\
\hline
\end{tabular}

SS; Standart Sapma, $\phi$;ndependent Samples T-Test

\section{Tartışma}

Halk sağlığı açısından dijital oyun bağımlıı̆̆ ve fiziksel inaktivite, çocukluk çağındaki obezite, tip 1 diyabet gibi bulaşıcı olmayan hastalıkların görülme oranını artırmakta ve ilerleyen yaşlarda daha büyük sağlık sorunlarıyla karşılaşılmasına yol açmaktadır. Bu çalışmada, ortaokul öğrencilerinde dijital oyun bağımlılı̆ı oranları araştırımış ve dijital oyun bağımlılı̆ı ile fiziksel aktivite ve uyku alışkanlıkları arasındaki ilişki incelenmiştir. Ülkemizde internet kullanımının gençler arasında oldukça yüksek bir seviyede olduğu bildirilmiştir $(19,20)$. Çalışmanın sonuçları incelendiğinde çalışmaya katılan öğrencilerin \%67'sinin dijital oyun oynama alışkanlığının olduğu ve oyun oynayan öğrenci grubunun \%6'sının günde üç saatten daha fazla süre dijital oyun oynadığı görülmüştür. Literatürde yer alan çalışmalarda gençlerde görülen internet kullanımı ile birlikte dijital oyun bağımılığı prevelansının \%15 ve altında olduğu ifade edilmiştir $(1,21,22)$. Diğer çalışmalardan farklı olarak Leung ve arkadaşlarının yaptığı çalışmada \%35'in üzerinde olduğu bildirilmiştir (22). Dijital oyun oynama alışkanlığının yaygınlık oranlarının farklıık göstermesi, çalışmalarda farklı tanı ölçütlerinin kullanılması, değişik yaş grupları ve kültürleri kapsaması ile açıklanabilir.

Çalısmaya katılan öğrencilerin çoğunluğunun (\%66) dijital bağımlılık göstermediği, \%9'unun riskli grupta, \%22'sinin bağımlı grupta olduğu ve \%3'ünün yüksek düzeyde bağımlı grup içinde yer aldığı tespit edilmiştir. Ülkemizde yapılan çalışmalar incelendiğinde ortaokul öğrencilerinin bağımlılık prevalansının \%328,8 arasında olduğu belirlenmiştir $(23,24)$. Çalışmamızın sonuçları yapılan diğer çalışmaların sonuçları ile paralellik göstermektedir.

Çalışmada öğrencinin babasının eğitim durumu "lise" olan öğrencilerin dijital oyun bağımlılığı ölçeği puanları daha yüksek olduğu görülmüştür. Literatürde yapılan birçok araştırmada, anne ve babanın eğitim 
seviyesi açısından oyun bağımlılığı düzeylerinin anlamlı biçimde farklılaştığı ve özetle ebeveynlerin eğitim seviyesi arttıkça çocuklarının oyun bağımlılı̆ı düzeyinin de arttığı sonucuna ulaşılmıştır (25,26,27).

Literatürde karşılaștığımız birçok çalıșmada bireyin oynadığı dijital oyun süresi ile oyun bağımlılığı düzeyi arasındaki ilişki değerlendirilmektedir. Fröolich ve arkadaşları yaptığı çalışmasında öğrencilerin günlük bilgisayar oyunu oynama sürelerine göre bağımlılık düzeylerinde anlamlı düzeyde farklılık olduğu görülmüştür ve bağımlılık düzeyi yüksek olanların günlük bilgisayar oyunu oynama süresinin dört saat ve üzeri olduğu görülmüştür (28). Bu çalışmada günde 3 saatten fazla oyun oynayan öğrencilerin bağımlıık düzeyinin yüksek olduğu tespit edilmiştir.

Literatürde yer alan birçok araştırmada çocuklarda fiziksel aktivite düzeyinin düşük olduğuna ilişkin araştırma bulgularına ulaşılmıştır (29). Bu çalışmaya katılan öğrencilerin de fiziksel aktivite ölçeği puanlarının düşük olması literatürle uyumlu bir sonuç olarak değerlendirilmektedir. Çalışmamızda fiziksel aktivite düzeyine etki edebilecek demografik veriler de incelenmiş ve öğrencilerin sınıf düzeyi ve ailenin ekonomik geliri azalmış fiziksel aktivite ile ilişkili parametreler olarak tespit edilmiştir.

Çalışmanın bulgularına göre öğrencilerin sınıf düzeyleri ile fiziksel aktivite ölçeği arasında anlamlı bir farklılık olduğu görülmüştür. Varyans analizi ile karşılaştırma sonuçlarına göre öğrencilerin fiziksel aktivite düzeylerinin sınıf düzeyleri yükseldikçe azaldığı bulunmuştur. Bilgin ve arkadaşları yaptıkları araştırmada da 6. ve 7. sınıf öğrencilerin toplam fiziksel aktivite puanlarının 8. sınıf öğrencilere göre yüksek bulduklarını bildirmişlerdir (30). Bu farkılık 8. sınıf öğrencilerinin boş zamanlarını liselere yerleşme sınavları gibi çeşitli sınavlara hazırlanma ile geçirmelerinden dolayı fiziksel aktivite için daha az zamanlarının kalmasından kaynaklanıyor olabildiği düşünülmektedir.

Günümüzde, çocuklar dışarıda, açık alanlarda, oyun parklarında veya spor sahalarında oyunlar oynamaktansa, internet kafelerde, evlerinde, play-station salonlarında dijital oyunlar oynamakta, bunun sonucu olarak çocukların fiziksel aktivite düzeyleri gittikçe düşmektedir. Bu çalışmada, Mannikkö ve arkadaşlarının çalışmasında olduğu gibi dijital oyun bağımlıı̆ı ile fiziksel aktivite düzeyi arasında bir ilişki elde edilmemiştir (31). Bunun araştırmanın kesitsel tasarımından kaynaklanabileceği düşünülmektedir. Mota ve arkadaşları internet ve bilgisayarın aşııı kullanımının, fiziksel aktivite düzeylerinin azalması ile ilişkili olduğunu bildirmiştir (32). Hazar ve arkadaşları da ortaokul öğrencilerinin dijital oyun bağımlılığı ile fiziksel aktivite düzeyi arasında negatif yönde ve anlamlı düzeyde bir ilişkinin olduğunu göstermiştir (33).

Türkiye'de internet bağımlılı̆ı ile uyku problemleri arasındaki ilişkiyi inceleyen bir araştırma 2019 yılında Bener ve arkadaşları tarafından yayınlanmıştır (34). 2350 öğrencinin dahil edildiği geniş spektrumlu bu çalışmada internet bağımlılığının uyku problemleri ve yorgunluk semptomlarına sebep olduğu görülmüştür. Hatay'da 1212 öğrencinin katılımıyla yapılan bir çalışmada internet bağımlılı̆ı ölçek puanı yüksek olan öğrencilerin düşük olanlara göre gece uyumaya daha geç gittiği, uykuya dalma süresinin daha uzun olduğu ve geceleri daha sık uyandığı bildirilmiştir (35). Bu çalışmada ise öğrencilerin dijital oyun oynama durumlarının uyku alışkanlıklarını ve oyun oynadıkları sürenin uyuma ve uyanma saatlerini değiştirmediği saptanmıştır. Bununla birlikte çalışmanın bulgularına göre öğrencilerin dijital oyun bağımlılı̆ı ve alt parametreleri ile uyku alışkanlıkları arasında yapılan çoklu analizlerde dijital oyun bağımlıı̆̆ının uyku alışkanlıklarını etkilemesi için bir risk faktörü olmadığı görülmüştür. Çalışmaya dahil olan öğrencilerin eğitimleri için düzenli bir saatte uyumaları ve uyanmaları gerekliliğinden dolayı dijital oyun bağımlıık durumlarının bu düzeni değiştirmediğini ön görmekteyiz.

Sonuç olarak, günümüzde internet bağımlılığı okul çağındaki çocuklarda gün geçtikçe artan ciddi bir problem olarak görülmektedir. Dünyadaki yenilikler, en son gelişmeler ve bilgiye ulaşmada en kolay yöntem olan internetten öğrencileri uzak tutmak çağımızda neredeyse imkansızdır. Bu çalışmada Ortaokul öğrencilerinde internet kullanımının artışı ile beraberinde gelen dijital oyun bağımlıı̆ı ile fiziksel aktivite seviyesi ve uyku alışkanlıkları arasında doğrusal bir ilişkisi olmadığı ancak üç saat ve daha fazla oyun oynayan öğrencilerin bağımlılık seviyeleri ciddi oranda artmış olduğu da net olarak görülmüştür. Elde edilen verilerin yalnızca bir bölgedeki iki okulda yer alan bireylerden elde edilmiş olması ve hazırlanan form ve uygulanan ölçeklerle sınırlı olması çalışmamızın kısıt|lıklarındandır. Uzayan oyun oyamama süreleri ile 
birlikte öğrencilerin fiziksel aktiviteye ayıracağı sürenin azalması ve inaktif yaşamdan kaynaklı uyku problemlerinin gelişebileceği ve böylesi önemli problemlerin çocuklara getirebileceği olası risklerin toplum tarafından bilinmesinin çocuklara, ailelere ve öğretmenlere anlatılarak farkındalık yaratımasının gerekli olduğu düşünülmektedir.

\section{Kaynaklar}

1. Van Rooij AJ, Schoenmakers TM, Vermulst AA, et al. Online video game addiction: identification of addicted adolescent gamers. Addiction 2011; 106(Suppl 1): 205-212.

2. Lau C, Stewart SL, Sarmiento C, et al. Who is at risk for problematic video gaming? Risk factors in problematic video gaming in clinically referred Canadian children and adolescents. Multimodal Technol Interact 2018; 2(Suppl 2): 1-16.

3. Gentile D. Pathological video-game use among youth ages 8 to 18: A national study. Psychol Sci 2009; 20(Suppl 5): 594-602.

4. Irmak AY, Erdoğan S. Ergen ve genç erişkinlerde dijital oyun bağımlıı̆ğ: güncel bir bakış. Turk Psikiyatri Derg 2016; 27(Suppl 2): 128-137.

5. Jeong EJ, Kim DJ, Lee DM. Why do some people become addicted to digital games more easily? A study of digital game addiction from a psychosocial health perspective. Hum-Comput Interact 2017; 33(Suppl 3): 199214.

6. Mihara S, Higuchi S. Cross-sectional and longitudinal epidemiological studies of Internet gaming disorder: A systematic review of the literature. Psychiatry Clin Neurosci 2017; 71(Suppl 7): 425-44.

7. Henchoz Y, Studer J, Deline S, et al. Video gaming disorder and sport and exercise in emerging adulthood: A longitudinal study. J Behav Med 2016; 42(Suppl.2): 105-111.

8. Ballard M, Gray M, Reilly J, Noggle M. Correlates of video game screen time among males: body mass physical activity, and other media use. Eat Behav 2009; 10(Suppl.3): 161-167.

9. Pontes HM, Griffiths MD. Internet gaming disorder and its associated cognitions and cognitive-related impairments: A systematic review using PRISMA guidelines. Rev Argent Cienc Comport 2015; 7(Suppl 3): 102108.

10. Rosen LD, Lim A, Felt J, et al. Media and technology use predicts ill-being among children, preteens and teenagers independent of the negative health impacts of exercise and eating habits. Comput Hum Behav 2014; 35: 364-375.

11. Mustafaoğlu R, Zirek E, Yasacı Z, Özdinçler AR. The negative effects of digital technology usage on children's development and health. Addicta: The Turkish Journal on Addictions 2018; 5(Suppl 2): 13-21.

12. Tomczyk $Ł$, Solecki R. Problematic internet use and protective factors related to family and free time activities among young people. Educational Sciences:Theory \& Practice 2019; 19(Suppl 3): 1-13.

13. Hazar Z, Tekkurşun DG, Namlı S, Türkeli A. Investıgatıon of the relatıonshıp between dıgıtal game addıctıon and physical activity levels of secondary school students. J Phys Educ Sport 2017; 11(Suppl 3): 320-332.

14. Hazar Z, Hazar M. Digital game addiction scale for children. J Hum Sci 2017; 14(Suppl 1): 203-216.

15. Kowalski KC, Crocker PR, Faulkner RA. Validation of the physical activity questionnaire for older children. Pediatr Exerc Sci 1997; 9(Suppl.2): 174-186.

16. Sert ZE, Temel AB. Illköğretim öğrencileri için fiziksel aktivite soru formunun Türk toplumuna uyarlanması: geçerlilik ve güvenilirlik çalışması. Dokuz Eylül Üniversitesi Hemşirelik Fakültesi Elektronik Dergisi 2014; 7(Suppl 2): 109-114.

17. Owens JA, Spirito A, Mc Guinn M. The children's sleep habits questionnaire (CSHQ): psychometric properties of a survey instrument for school-aged children. Sleep 2000; 23(Suppl 8): 1043-1052.

18. Fiş NP, Arman A, Ay $P$ et al. Çocuk uyku alışkanlıkları anketinin Türkçe geçerliliği ve güvenilirliği. Anadolu Psikiyatri Derg 2010; 11(Suppl 2): 151-160.

19. Karababa A. Examining internet addiction of early adolescents in terms of parenting styles. Türk Psikolojik Danışma ve Rehberlik Dergisi 2020; 10(Suppl 57): 229-254.

20. Tahiroglu AY, Celik GG, Uzel M, et al. Internet use among Turkish adolescents. Cyber Psychol Behav Soc Netw 2008; 11 (Suppl 5): 537-543.

21. Hur MH. Demographic, habitual, and socioeconomic determinants of Internet addiction disorder: an empirical study of Korean teenagers. Cyber Psychol Behav Soc Netw 2006; 9(Suppl 5): 514-525.

22. Leung L. Net-generation attributes and seductive properties of the internet as predictors of online activities and internet addiction. Cyber Psychol Behav Soc Netw 2004; 7(Suppl 3): 333-348. 
23. Özgur H. Online Game Addiction among Turkish adolescents: The effect of Internet parenting style. Malays Online J Educ Technol 2019; 7(Suppl 1): 47-68.

24. Sahin M, Gumus YY, Dincel S. Game addiction and academic achievement. Educ Psychol Rev 2016; 36(Suppl 9): $1533-1543$.

25. Gökçearslan Ş, Durakoğlu A. Ortaokul öğrencilerinin bilgisayar oyunu bağımlılık düzeylerinin çeşitli değişkenlere göre incelenmesi. Dicle Üniversitesi Ziya Gökalp Eğitim Fakültesi Dergisi 2014; 23(Suppl 23): 419-435.

26. Talan T, Kalınkara Y. Ortaokul öğrencilerinin dijital oyun oynama eğilimlerinin ve bilgisayar oyun bağımlılık düzeylerinin incelenmesi: Malatya ili örneği. Öğretim Teknolojileri ve Öğretmen Eğitimi Dergisi 2020; 9(Suppl 1): $1-13$.

27. Hazar Z, Tekkurşun DG, Dalkıran H. Ortaokul öğrencilerinin geleneksel oyun ve dijital oyun algılarının incelenmesi: Karşılaştırmalı metafor çalışması. Spormetre Beden Eğitimi ve Spor Bilimleri Dergisi 2017; 15(Suppl 4): 179-190.

28. Frölich J, Lehmkuhl G, Orawa H, Bromba M. Computer game misuse and addiction of adolescents in a clinically referred study sample. Comput Hum Behav 2016; 55: 9-15.

29. Chi $X$, Hong X, Chen $X$. Profiles and sociodemographic correlates of Internet addiction in early adolescents in southern China. Addict Behav 2020; 12(Suppl 4): 106-108.

30. Bilgin E, Bulca Y, Demirhan G. Fiziksel aktivite düzeyi, fiziksel uygunluk, akademik başarı ve akademik benlik kavramı arasındaki ilişkinin incelenmesi. Eğitim ve Bilim 2020; 45(Suppl.20): 46-48.

31. Männikkö N, Billieux J, Kääriäinen M. Problematic digital gaming behavior and its relation to the psychological, social and physical health of Finnish adolescents and young adults. J Behav Addict 2015; 4(Suppl 4): 281-288.

32. Mota J, Ribeiro J, Santos MP, Gomes H. Obesity, physical activity, computer use, and TV viewing in Portuguese adolescents. Pediatr Exerc Sci 2006; 18(Suppl 1): 113-121.

33. Hazar Z, Hazar K, Gökyürek B, Hazar M, et al. Ortaokul öğrencilerinin oyunsallık, dijital oyun bağımlılı̆ı ve saldırganlık düzeyleri arasındaki ilişkinin çeşitli değişkenler açısından incelenmesi. Journal of Human Sciences 2017; 14(Suppl 4): 4320-4332.

34. Bener A, Yildirim E, Torun P, Çatan F. Internet addiction, fatigue, and sleep problems among adolescent students: a large-scale study. Int J Ment Health Addict 2019; 17(Suppl 4): 959-969.

35. Ekinci Ö, Celik T, Savaş N, Toros F. Association between Internet use and sleep problems in adolescents. Noro Psikiyatr Ars 2014; 51(Suppl 2): 120-128. 